\title{
História, subjetividade e especulação nas personagens machadianas
}

\author{
History, subjectivity and speculation in Machado de Assis' characters
}

Poliana dos Santos ${ }^{1}$

Resumo: Este trabalho pretende, por meio da análise literária e histórica, examinar como algumas personagens machadianas têm o seu comportamento moldado pelas condições econômicas brasileiras, especificamente o caráter especulativo que marcou a transição do Império para a República. Para tanto, tomar-se-á como objeto de estudo alguns contos do escritor, cuja importância se dá não apenas pelo seu caráter de testemunho e o seu papel artístico, mas também pela elaboração de uma consciência e reflexão histórica imerso na narrativa.

Palavras-chave: história, literatura, subjetividade, especulação

Abstract: This paper aims, through the literary and historical analysis, examine how some Machado de Assis' characters have their behavior shaped by Brazilian economic conditions, specifically the speculative character that marked the transition from Empire to Republic. To do so, it will be taken as an object of study some write's tales, whose importance is given not only by his character's testimony and his artistic role, but also for developing an awareness and historical reflection immersed in the narrative.

Keywords: history, literature, subjectivity, speculation

Machado de Assis, o historiador! O ofício laborioso de pensar a história e reinventá-la na ficção é conferido ao escritor tanto por historiadores quanto por críticos literários, como Chalhoub (2003), Bosi (2007), Gledson (2006), Roberto Schwartz (2000) e Raimundo Faoro (1974). É fato, a literatura de Machado de Assis representa de maneira muito elegante a ambiguidade de sua época. No entanto, apesar do reconhecimento do caráter testemunhal das obras machadianas, pouco se refletiu sobre a visão historiográfica do autor. Ou seja, que tipo de historiador é Machado de Assis? Como ele vê a história? Como ele constrói a relação entre os homens e o conjunto da sociedade, o indivíduo e o coletivo? E mais, qual o poder da individualidade humana na construção dos acontecimentos? E onde estaria o papel das ideias no campo social?

Lendo alguns romances e contos do escritor, percebe-se que seus livros dão conta de todas essas questões, apresentando uma leitura singular do tempo e das pessoas. A sua criatividade literária

\footnotetext{
1 Poliana dos Santos possui graduação em história pela Universidade Federal de Alagoas e mestrado em Estudos Literários pela Faculdade de Letras da mesma universidade. Atualmente é doutoranda em História Social pela Universidade de São Paulo.
} 
chega antecipar alguns conceitos históricos que serão elaborados somente nos anos de 1930, com a escola dos Annales.

Posto isso, pretendo analisar alguns contos que tratem da concepção de história de Machado de Assis por meio de seus personagens e do contexto. Para tanto, este trabalho se organiza em três partes: 1. Machado de Assis, laborando a história..., busca-se compreender a percepção historiográfica do autor; 2. Natureza e especulação, procura-se analisar como os seres fictícios machadianos se articulam com as vicissitudes e o contexto social; 3. Da essência do homem à condição material: alguns contos machadianos, no qual analisados seis contos a partir das personagens e de suas reações aos ditames históricos: Capítulo dos chapéus, Teoria do medalhão, Fulano, Evolução, Anedota pecuniária e 0 anel de Polícrates².

\section{Machado de Assis, laborando a história...}

Para Machado de Assis, história e imaginação não são saberes antagônicos, mas complementares. O imaginário contém um forte poder cognitivo para compreensão e produção do conhecimento social, suprindo as lacunas ou vazios que também fazem o tecido histórico. No romance Esaú e Jacó (2012, p. 64), ele afirma:

Há nos mais graves acontecimentos, muitos pormenores que se perdem, outros que a imaginação inventa para suprir os perdidos, e nem por isso a história morre.

Portanto, a história se alimenta tanto do real quanto da imaginação para remontar as complexas relações sociais. E os grandes eventos estão repletos de pormenores que desaparecem no tempo. Esse detalhe perdido ou esquecido é constituinte e revelador dos homens e da sociedade. Conforme o literato, o pequeno faz a história e é preciso fisgá-lo. O papel da ficção seria alinhavar 0 ponto que foi rompido no tecido histórico com aquilo que é diminuto. Esse diálogo com a literatura consente na existência de uma história viva e enriquecedora. $\mathrm{E}$ o invisível tem lugar preponderante na construção dos acontecimentos: "o tempo é um tecido invisível em que se pode bordar tudo, uma flor, um pássaro, uma dama, um castelo, um túmulo. Também se pode bordar nada. Nada em cima de invisível é a mais sutil obra deste mundo, e acaso de outro" (Ibid., p. 64).

O comezinho e o acaso compõem o tempo, bordam a história. Bordados estes feitos igualmente de nada, da não construção. Enfim, o escritor acredita que o saber histórico não pode

2 Os contos que serão citados neste artigo fazem parte da antologia organizada por John Gledson. Cf. ASSIS, Machado de. Contos: uma antologia. São Paulo: Companhia das Letras, 1998. v. 1 e 2. As citações serão acompanhadas somente com 0 número do volume e da página. 
prescindir dos buracos, do insignificante, daquilo que está escondido, do que não se pode ver. As ideias nesse tempo invisível são voláteis, perdem a paternidade, ganham a vida, são refeitas e reinventadas, passam de mão em mão, derrubando fronteiras, girando e circulando entre os dias, as classes sociais e os espaços.

Ha frases assim felizes. Nascem modestamente, como a gente pobre; quando menos pensam, estão governando o mundo, à semelhança das ideias. As próprias ideias nem sempre conservam o nome do pai; muitas aparecem órfãs, nascidas de nada e de ninguém. Cada um pega delas, verte-as como pode, e vai levá-las à feira, onde todos as têm por suas (Ibid., p. 91-92).

Machado de Assis é um historiador atual, porque pensa a história a partir de seus elementos micros, porque compreende a vasta relação e imbricações que se realizam no campo das mentalidades, porque dá atenção às trocas e apropriações que ocorrem entre as ideias e a vida material. E, ainda, ele vê na ficção uma poderosa força para explicar a sociedade. Mas onde entraria 0 indivíduo? Para o escritor, a história não anula o pessoal ou o particular. A individualidade do sujeito procura uma negociação com a sua época, com as condições materiais do seu presente. Às vezes os indivíduos são forçados a manter certas combinações; às vezes seus traços típicos casam muito bem com as demandas do momento. Só em duas situações os acordos são impossíveis, quando a personalidade tem uma característica de resistência ou possui indícios patológicos.

\section{Natureza e Especulação}

Machado de Assis viveu num período de transição, que remete a um universo escravocrata e, ao mesmo tempo, liberal. Seus romances e contos aludem a eventos do Império e do começo da República, expondo as várias formas de sociabilidade que se estabelecem nas classes sociais. Aos nossos olhos é apresentado um desfile de profissões, de sujeitos com práticas e valores compartilhados. Mas cada um reage distintamente às imposições, contingências e tramas da existência coletiva.

Assim, sob a capa de uma vida corriqueira e socialmente impressa nos teatros, nas visitas, nos passeios, na rotina doméstica e pública, as personagens machadianas revelam outro mundo. Um recanto escondido e involuntário da alma humana, que coexiste em tensão com fatores sociais e específicos do país. E esse lugar é a morada das paixões, afetos, desejos, medos, atos bizarros e até cruéis. Na escrita de Machado de Assis, uma luta é travada no coração do homem, conflito entre Eros, que liga a humanidade, e pulsões de morte, vontade destrutiva, egoísta e cobiçosa; o mal-estar da 
civilização como denominou Freud (2011). Talvez seja por isso que algumas das suas criaturas tenham um tanto de inesgotável, uma busca nunca saciada, um toque de violência que colide com a norma da maioria, como os protagonistas de Verba testamentária (1998) e A causa secreta (1998). Em razão disso, Candido (2004, p. 17, grifo do autor) caracteriza o escritor como "enigmático e bifronte [...] escondendo um mundo estranho e original sob a neutralidade aparente das suas histórias que todos podiam ler".

Essa tensão entre indivíduo e sociedade é representada nos contos de modo dialético. A existência social não é um imperativo exclusivo na constituição do ser. Este também interfere e deixa a sua marca no espaço e no fazer coletivo. Não são apenas as bases materiais que predominam nas relações entre os sujeitos. As categorias psicológicas e do inconsciente são igualmente elementos de força. Não obstante, para alcançar o sucesso é preciso o disfarce, a máscara, cujas fendas são sutilmente descortinadas pelo narrador e reveladas ao leitor (Cf. BOSI, 1982).

0 autor insere suas personagens no contexto de alargamento e exploração das forças econômicas, que desemboca na especulação financeira. O mundo dos negócios e a vida se transformam numa loteria, um jogo de azar ou sorte, uma corrida pelo lucro fácil. É esse espírito de oportunismos e arranjos que vão compor parte substancial de suas criaturas ficcionais. As figuras fictícias, qualificadas por uma essência egoísta, duvidosa, ambiciosa e, muitas vezes, perniciosa, encontraram um ambiente social propício para o exercício do seu desejo.

As personagens não especulam apenas com a moeda. As suas ações e sentimentos são comumente especulativos: as ideias, os amores, a política, a família, o matrimônio são partes dos utensílios para se dar bem, para subir de escala. Existe, contudo, aqueles que resistem a essa lógica, como explica Bosi (2007, p. 45) a respeito de Helena, a heroína do romance homônimo, que opta por morrer a passar por calculista. Entretanto, aqueles que decidiram apostar nem sempre saem vencedores. Algumas figuras possuidoras de uma natureza incontrolável são incapazes de se manter na competição, isolando-se ou perdendo tudo o que ganharam.

Esse caráter especulativo, internalizado nos seus textos, é eminente na conjuntura histórica do Brasil da segunda metade do século XIX e começo do XX. Como aponta Caio Prado Junior (2006, p. 192), depois de 1850, data do fim do tráfico africano, a nação passou por um período de transformação econômica, com a expansão da agricultura, o advento de uma indústria incipiente, o aumento no número de bancos, de transporte público, gás e estrada de ferro. Tais empreendimentos foram incitados pela especulação do capital privado e as emissões de papel-moeda. 0 momento deu início a uma sede desenfreada pelo dinheiro e pela ambição material. Por meio de transações nem sempre legítimas e de um novo espírito aventureiro, muitas fortunas caíram em desgraça, e outras surgiram da noite para o dia. Era a febre das ações e do jogo cambial que culminou na crise de 1891, já no governo 
republicano. Com efeito, a vida cotidiana é afetada, ganhando mais velocidade e oferecendo possibilidade de ascensão social. Surge uma nova mentalidade, mais cosmopolita, impressionada com a moda europeia. Era a vez do arrivista e de um assentado superficialismo.

Astrojildo Pereira (1959, p. 46), de maneira perspicaz, afirma que essa é a ocasião em que Machado de Assis "transita sucessivamente para a puberdade e a adolescência, os sentidos aguçados para a vida que borbulha ao seu redor, integrando-se, fibra por fibra, no movimento ascensional que começa a imprimir nova fisionomia ao país". Em suma, todas essas modificações no terreno nacional, observadas e vividas pelo autor, serão recompostas artisticamente nas suas obras.

Nota-se que a obra machadiana se conjuga em três perspectivas. $O$ fator subjetivo, que versa sobre a essência peculiar dos seres; o social, numa direção mais ampla das relações grupais, que exige certa polidez no trato com o outro, fórmulas e hábitos convencionalmente aceitos por todos; e o representativo, que traz traços específicos da história do país. É a articulação desses componentes que sintetizaria a definição que o escritor (ASSIS, 2009, p. 153) possui de arte. "[...] Eu tenho a inqualificável monomania de não tomar a arte pela arte, mas a arte, como a toma Hugo, missão social, missão nacional e missão humana".

\section{Da essência do homem à condição material: alguns contos machadianos}

No conto o Capítulo dos chapéus a realidade especular se dá por meio de um fato ordinário. 0 enredo, que se passa em 1879, relata a desavença entre Mariana, uma esposa dedicada e paciente, e seu o marido, o advogado Conrado Seabra. A mola da discussão era o fato deste último usar um chapéu que não se ajustaria ao ambiente da cidade e a sua posição bacharelesca. A persistência do cônjuge em continuar usando o apetrecho, gera na mulher um sentimento de revolta, que será o novelo da intriga. Depois, fica-se sabendo que o pedido da moça era causado pelo incômodo confesso de seu pai, habituado à elegância da casaca.

O conflito matrimonial induz a quebra da rotina doméstica. Na companhia da amiga Sofia, Mariana decide fazer um passeio na agitada Rua do Ouvidor, onde irá encontrar o seu primeiro namorado, Dr. Viçoso, rapaz já egresso da Europa e ex-presidente de uma província do Sul. Todas as personagens envolvidas possuem características próprias e serão definidas pelos chapéus que usam. O acessório tem uma função simbólica, representando, a um só tempo, a coexistência conflituosa entre o passado e o presente, as mudanças do comportamento social, a reificação do espírito, a vaidade humana. Não é sem importância o plural que encerra o título do conto. Tamanho significado está resumido na teoria levantada por Conrado: "[...] o chapéu é a integração do homem, um prolongamento da cabeça, um complemento decretado ab eterno; ninguém o pode trocar sem mutilação" (v. 2, p. 95). 
A tensão entre o antigo e o novo se apresenta, primeiramente, na figura do pai de Mariana. Tudo nele cheira a um tempo remoto. Homem velho, pausado, acostumado à solenidade da casaca e à austeridade da cartola, aferrado sempre aos mesmos costumes. Vivia de saudade. O chapéu do genro, baixo, simples e leve era indício do fim de uma tradição, e o advento dos ares modernos. 0 choque de temporalidades distintas é montado por meio do encontro entre diferentes chapéus. O sogro vê o advogado conversando com algumas pessoas, e sente-se aborrecido:

Como supor que ele aprovasse o chapéu do genro? Suportava-o calado, em atenção às qualidades da pessoa; nada mais. Acontecera-Ihe, porém, naquele dia, vê-lo de relance na rua, de palestra com outros chapéus altos de homens públicos, e nunca the pareceu tão torpe. De noite, encontrando com a filha sozinha, abriu-lhe o coração; pintou-Ihe o chapéu baixo como a abominação das abominações, e instou com ela para que o fizesse desterrar (v. 2, p. 94, grifo meu).

O olhar do velho, assim como o de sua filha, confunde-se, em alguns momentos, com a perspectiva do narrador que, estando em terceira pessoa, faz uso frequente do discurso indireto livre. As coisas e os homens se misturam a ponto de o indivíduo se tornar o complemento do próprio objeto. Isso fica claro até mesmo no movimento das personagens, expresso não pela pessoa em si, mas pela indumentária: "os tacões de Sofia desceram a escada, compassadamente" (v. 2, p. 98); "o rumor das saias chamou a atenção de uns vinte deputados" (v. 2, p. 104). A reificação do ser humano é ainda mais forte na passagem em que as duas mulheres estão na Rua do Ouvidor. Centro vivo e agitado da cidade carioca, o logradouro é conhecido por suas lojas, cafés, os jornais e as novidades europeias. Espaço de sociabilidade para observar e ser observado. No entanto, a visão que impera é a da fragmentação. Estando paradas ou caminhando, as pessoas são identificadas apenas por seus chapéus masculinos ou femininos:

[...] Da Janela podia gozar a rua, sem atropelo. Recostou-se; Sofia veio ter com ela. Alguns chapéus masculinos, parados, começaram a fitá-las; outros, passando fazia a mesma coisa. [...] Sofia contava-lhe a história de alguns chapéus, - ou, mais corretamente, as aventuras. Um deles merecia os pensamentos de Fulana; outro andava derretido por Sicrana, e ela por ele, tanto que eram certos na rua do Ouvidor às quartas e sábados, entre duas e três horas. Mariana ouvia aturdida. Na verdade, o chapéu era bonito, trazia uma linda gravata, e possuía um ar entre elegante e pelintra, mas... (v. 2, p. 100).

É significativa a diferença que separa as duas amigas. Sofia é o tipo de personalidade especulativa, joga com os amores. O narrador a define como alta, forte, honesta, mas namoradeira por 
natureza. Seus gestos eram calculados, derramando olhares para todos os lados. O tamanho do chapéu que usava condizia, portanto, com o ar de superioridade e veleidade que a dominava. A Rua do Ouvidor lhe pertencia, por isso tinha a destreza e a facilidade de contornar a gente que encontrava pelo caminho. Essa imagem especular também tecia a aparência de Viçoso, cujo nome remete imediatamente a uma judiciosa exuberância. "Tinha na mão um chapéu novo, alto, preto, grave, presidencial, administrativo, um chapéu adequado à pessoa e às ambições" (v. 2, p. 101). 0 interesse que eles tinham em comum pelo Jockey Club diz muito sobre o grau das suas cobiças; e o prazer que sentiam no risco. Sofia, por exemplo, gostava do esporte, porque the dava emoções fortes. Pode-se perceber que a atitude dessas personagens conduz adequadamente para aquele espírito oportunista e ganancioso que despontou na segunda metade do século XIX.

Num mundo de chapéus, a única que parecia não usá-los era Mariana. Figura de resistência nesse universo matemático e interesseiro, ela era quieta, indiferente e monótona. A agitação das ruas, o tráfego de pessoas, a efervescência da cidade era motivo de confusão e angustia interior. Em razão disso, o passeio com a colega se transformou em suplício e sentimento de raiva, que suportou com a máscara da lisonja e do sorriso, pois temia que o desentendimento com o marido fosse publicamente exposto.

Da prática ao fundamento, o conto Teoria do medalhão é o esboço lógico de como calcular e triunfar. Nele se tem uma aprendizagem. No aniversário de maioridade do filho, o pai ensina ao rapaz como alcançar o prestígio através de um receituário rigoroso. A vida é tomada como uma enorme loteria e os prêmios são para poucos. É preciso apostar, mas para vencer, e não cair na obscuridade comum, é imprescindível seguir certos princípios. Aqui a especulação chega ao seu ponto máximo, sendo o sentido e o alvo da própria existência. 0 objetivo central é a subtração da individualidade, de qualquer ideia que forneça uma mortificação ao espírito. Não ter nenhum pensamento específico na alma, mas tê-lo todo em proveito das mais diversas situações, eis o que diferencia um medalhão profissional do amador.

A figura paterna doutrina o jovem ao puro artificialismo. Para tanto, aconselha-o a ler resumos de retórica; a jogar voltarete, whist e bilhar, atividades que exigem algum molejo e uma cota de malandragem; a evitar a solidão; a ir à livraria para ser visto e falar do alheio; a utilizar frases feitas e fórmulas consagradas; e a adotar a metafísica política. A "arte difícil de pensar o pensado" (v. 1, p. 332).

Com humor e uma fina ironia, Machado de Assis incute na fala paternal, o tom grave e sério do absurdo, desvelando uma verdade profunda e cruel: o disparatado é o óbvio. Se o indivíduo quer tomar parte das benesses sociais tem que aceitar as regras da exterioridade. Nesse caso, Bosi (1982, p. 442) comenta que a máscara é uma defesa contra a pobreza e a humilhação, sendo, portanto, 
indispensável. 0 verdadeiro medalhão, cuja idade ideal é 45 anos, é aquele que atingiu a plena inópia, tornando-se homem reclame, ornato. A publicidade seria a alma do negócio. O referencial lógico dessa panaceia da vida social é o Príncipe de Machiavelli, que o pai sugere como leitura ao filho.

Os contos Fulano e Evolução são modelares nesse aspecto. Os protagonistas estão naquela fase acabada do medalhão, a idade dos 45 anos. 0 primeiro conta a história de Fulano Beltrão que antes dos 40 anos vivia no ostracismo, porém, passado esse período, torna-se uma espécie de rótulo, sendo anunciado e fazendo-se anunciar nas páginas dos jornais. A sua prática esportiva era também 0 voltarete. Sob o convite do narrador, o leitor é convocado a participar da abertura do testamento da ilustre personagem. A partir disso, fica-se sabendo dos episódios que marcaram a sua biografia. A perspectiva daquele que narra não é somente a de um amigo do falecido, mas também daquele que lê os periódicos. Em consequência, a narração é continuamente datada. Os atos de Fulano eram todos computados e visando à imprensa: deu um baile para comemorar a vitória de Riachuelo na Guerra do Paraguai, antes mesmo de saber o resultado da batalha, constando nos jornais de 1865; doou um soberbo castiçal de prata para igreja de Lampadosa; mandou esculpir na Itália um mausoléu para esposa, que antes foi exposto, durante quase um mês, à vista de todos na Rua do Ouvidor. Tudo isso é sabido pelos periódicos. Até mesmo a moléstia de Fulano estava estampada nas folhas jornalísticas: "na manhã do dia em que morreu ainda ouviu ler os jornais, e num deles uma pequena comunicação relativamente à sua moléstia, o que de algum modo pareceu reanimá-lo. Mas para a trade enfraqueceu um pouco; à noite expirou".

A falta de opinião, qualidade primordial num medalhão, era igualmente uma característica da personagem: "não tinha ideias políticas, dispunha de um desses temperamentos que substituem as ideias, e fazem crer que um homem pensa, quando simplesmente transpira" (v. 2, p. 150). No entanto, a cartilha para o sucesso não foi seguida à risca. Não era um completo medalhão. Ao entrar para política, do lado dos conservadores, mostrou-se vibrante e ostentoso, o que fez perder a eleição quando os liberais ascenderam novamente ao poder. "Este foi, talvez, o ponto mais fraco da vida do meu amigo", diz o narrador (v. 2, loc. cit.).

É expressiva a denominação dada ao protagonista, Fulano Beltrão. Tal designação alude não só a uma certa dubiedade, mas a condição a qual o indivíduo chegou, isto é, a nulidade interior. Daí surge o paradoxo. Apesar de ser visto e lembrado por todos, sendo nome indelével nos jornais, o sujeito se constitui como indeterminado. Alguém que é e não é, pessoa que não se sabe. Candido (2004, p. 23) explica que a identidade é um dos problemas fundamentais na obra machadiana: "quem sou eu? O que sou eu? Em que medida eu só existo por meio dos outros? Eu sou mais autêntico quando penso ou quando existo? Haverá mais de um ser em mim? Eis algumas perguntas que parecem formar o substrato dos seus contos e romance". 
O espelho (1998) é um conto que discute energicamente essas questões. A narração de Jacobina sobre a solidão que sofreu, durante uma temporada no sítio da sua tia, é aterrorizadora. Distante das relações sociais aparentes, metaforizadas pela sua farda de alferes, ele não reconhece a si próprio. Seu reflexo no espelho é vago, difuso e esfumaçado. Um fantasma. Sua imagem só ganha corporeidade quando põe o uniforme. 0 vidro reflete o modo como os outros o enxergam, a sua momentânea alma exterior. De posse novamente do externo, ele se sente em paz consigo mesmo.

A respeito de Evolução, destaca-se outro figurão de êxito na jogatina social: Benedito. Como a alcunha já indica é uma criatura abençoada, dispondo-se bem das tacadas que dá. Há também nele a falta de originalidade, todavia, possuía o "estojo dos assuntos", aonde podia apanhar toda sorte de ideias. Diferente da personagem anteriormente citada, era um tipo pacato, sem arroubos políticos, por conseguinte, sabia fazer de qualquer conceito algo utilitário. "Era assim que ele conseguia ajustar uma espécie de ateísmo vago com duas irmandades que fundou, não sei se na Gávea, na Tijuca ou no Engenho Velho. Usava assim, promiscuamente, a devoção, a irreligião e as meias de seda" (v. 2, p. 202). Estamos diante do verdadeiro medalhão. Homem de 45 anos, o seu disfarce no mundo exterior é simbolizado pela tintura preta que usava para esconder os cabelos brancos.

No geral, o enredo descreve como uma ideia, formulada pelo narrador, foi apropriada por Benedito. A sentença - "eu comparo o Brasil a uma criança que está engatinhando; só começará a andar quando tiver muitas estradas de ferro" (v. 2, loc. cit.) -, é roubada pelo protagonista durante uma conversa casual, numa viagem de trem. Ao longo do tempo, ela vai sendo reutilizada em diversas situações. Benedito faz um trabalho de pescaria; primeiro atribuindo o aforismo ao colega - o senhor dizia..., depois pluraliza a responsabilidade na exposição do pensamento - nós dizíamos..., e finalmente o assenhoreia por inteiro - dizia eu... Destarte, Bosi (1982, p. 454) comenta que o sistema desse relato ficcional gravita em torno do eixo pronominal tu-nós-eu.

Tanto em Fulano quanto em Evolução, observa-se a prática exemplar do arrivismo. Ardilosos e ajustados à nova ordem da sociedade, as personagens centrais aliam a vontade de poder às circunstâncias históricas. 0 mundo aberto ao mais forte, e este não é o mais honesto, permite uma crescente mobilidade individual. 0 contexto histórico é o da expansão e da racionalidade capitalista que vai tomando as suas cores no país, de maneira muito matizada e assimétrica.

Nos textos, natureza e sociedade se conjugam. E "a luta pelo dinheiro e pelo status aparece como prolongamento dos instintos" (BOSI, 1982, p. 451). Machado de Assis constrói personalidades que, inseridas nesse universo de especulação e competição, reagem de modo bastante singular, conforme a intensidade dos seus desejos. Na busca inefável para enriquecer e possuidoras de uma paixão desmedida, algumas figuras perdem ou vendem tudo. 
Vale notar que Faoro (1974, p. 18) observou que nem toda a riqueza das personagens machadianas era obtida através da herança e do casamento. As grandes carreiras eram alcançadas pela "especulação afortunada", pelo "lucro como artigo de fé". Havia prosperidades advindas dos acertos em volta das oscilações das ações financeiras. Destaca-se nessa fileira "Procópio Dias (laiá Garcia), o Palha (Quincas Borba), o Santos e o Nóbrega (Esaú e Jacó)".

Ainda segundo Faoro (1974, p. 8), a concepção machadiana - de que as estruturas sociais seriam movidas pelas paixões e afetos individuais -, estava ligada aos seus "preconceitos de moralista" e ao seu distanciamento da "formação do historiador do século XIX". No entanto, vale ressaltar que Machado de Assis não se prendia a paradigmas, especialmente aos preceitos historiográficos desse século, demasiado metódicos e limitadores. $O$ escritor intuiu que os sistemas humanos não são resultados puros dos fatos e das condições históricas. E que os impulsos individuais atuam no emaranhado coletivo, não podendo ser anulados. Nesse caso, o autor foi um antecipador das novas correntes históricas, que irradiaram na primeira metade do século $X X$, quando a história passou a ser pensada também a partir do particular e da mentalidade. Se formos pensar Machado de Assis como um historiador, que tipo de profissional ele seria? Com certeza, um historiador moderno, que busca a multiplicidade, que não reduz a cultura a um mero instrumento da classe dominante, ou instância subordinada ao determinismo econômico.

$O$ atrelamento entre as paixões e a sociedade, nos contos do escritor, parece estar conectado a uma concepção de natureza espinosana ${ }^{3}$. Espinosa (2008) acreditava que a essência do homem é o

\footnotetext{
3 Vale dizer que Machado de Assis (2009, p. 242) era um admirador de Espinosa e escreveu um poema homônimo do filósofo. Também guardava em sua biblioteca dois livros da autoria do pensador: o primeiro volume das obras completa em francês, publicado em 1873, e que continha os Princípios da filosofia cartesiana e Pensamentos metafísicos; e também o segundo volume das obras completas, de 1872, encerrando o Tratado Teológico-Político (OLIVEIRA, 2014, p. 342-343).
}

\section{Spinoza}

Gosto de ver-te, grave e solitário, Sob o fumo de esquálida candeia, Nas mãos a ferramenta de operário, E na cabeça a coruscante ideia.

E enquanto o pensamento delineia Uma filosofia, o pão diário A tua mão a labuta granjeia $E$ achas na independência o teu salário.

Soem cá fora agitações e lutas, Sibile o bafo aspérrimo do inverno, Tu trabalhas, tu pensas, e executas

Sóbrio, tranquilo, desvelado e terno, A lei comum, e morres, e transmutas O suado labor no prêmio eterno. 
desejo ou o apetite. Para além de uma moral de bem ou mal, o ser humano se esforça para aumentar a sua potência de agir e pensar com a finalidade de preservar e conservar a sua existência. Nesse sentido, o mau só existe na medida em que minha potência é diminuída, ou seja, quando me encontro em estado de tristeza; e uma coisa é boa na proporção que eu a desejo. Portanto, são os afetos, de diferentes modos e manifestações, que movem o homem: o amor, a cobiça, a inveja, a luxúria, a avareza, o arrependimento, a saudade, a comiseração, crueldade, etc. 0 indivíduo, enfim, não é um ser absoluto, cuja ação é determinada apenas por ele mesmo. Seu modo de vida é acompanhado por causas desconhecidas. Sua instabilidade e impotência resultam da sua própria natureza, isto é, das suas afeições. Faz parte da índole humana, então, o caráter invejoso, ambicioso e egoísta.

As personagens, estudadas aqui, parecem se ajustar assaz nesse conceito. Em face dessa natureza, o narrador machadiano procura compreender a alma do homem, sem julgá-lo ou criar juízo de valor. Por meio do comedimento e da anedota, o ponto de vista narrativo busca observar aquilo que as pessoas são. Desejosas e inconstantes, as criaturas do autor são dissimuladas, fingidas, porém, por necessidade, para assegurarem a si próprias no mundo. Elas tentam amoldar as suas paixões de acordo com os padrões e as vantagens sociais, aproveitando-se das demandas do tempo. $E$ isso é feito, muitas vezes, sem a tomada de consciência.

No que tange aqueles indivíduos que trocam, vendem ou perdem tudo por causa de algum impulso, percebe-se um desequilibrio entre os seus apetites e as normas sociais. Alimentados pela atmosfera arrivista, eles têm as suas veleidades excitadas ao máximo, ultrapassando os limites socialmente impostos.

Em Anedota Pecuniária, Falcão é um velho, caracterizado pela voracidade do lucro. A gana argentária é tamanha que o leva a se desfazer das duas sobrinhas. Uma, vende por dez contos de réis, em razão de um prejuízo nas vendas de ações; e a outra, troca por uma coleção de moedas. Ave de rapina, como o nome então indica, as feições do seu rosto tem um quê de animalesco e calculista: "olhar felino" e "dois beiços, mestres de cálculo" (v. 2, p 108). Vivendo na penúria, embora quase milionário, o dinheiro era tido como objeto de contemplação e erotismo. É com o olhar de apaixonado, e uma percepção sensualista, que ele cobiça a compilação numismática do amigo: "Falcão saiu dali com a coleção na alma: falou dela à sobrinha, e, imaginariamente, desarrumou e tornou a arrumar as moedas, como um amante desgrenha a amante para toucá-la outra vez" (v. 2, p. 17).

Nessa intriga, não é o sucesso e o brilho aparente que se busca, mas o acúmulo primitivo e transloucado de capital, a ponto de se negar os entes amados; de cair numa completa solidão, apenas compensada pelo ganho do dinheiro em si. $O$ isolamento e a tristeza que Falcão sentiu, após vender a

O escritor também foi influenciado pelas ideias que Montaigne e Pascal desenvolveram sobre a natureza humana. Um artigo interessante sobre o contato do autor com esses filósofos pode ser vista em Afrânio Coutinho (2011). 
primeira sobrinha, não resultaram em experiência, levando a permuta do segundo parente. Isso porque a verdadeira mulher e o real matrimônio são a riqueza e a possibilidade de sempre obter mais, razão que talvez explique o fato de nunca ter se casado. Nesse sentido, o conto dá relevo às vendas das ações cambiais e ao risco das operações financeiras.

Os gestos e as ações da figura central são extensões da selvageria social e econômica, somando-se uma porção compulsiva e infinda que classifica o seu ser. Seja nas negociatas ou nos vínculos afetivos do velho avarento, é a bestialidade que impera. Desse modo, ele fareja as baixas nas ações, "lambendo com os olhos os montes de libras e francos" (v. 2, p. 109, grifo meu), amando a sobrinha com um amor de cão.

$\mathrm{O}$ avesso de tal personagem é Xavier, de $\mathrm{O}$ anel de Polícrates ${ }^{4}$. $\mathrm{O}$ que Falcão acumulava em excesso, ele gastava. A narrativa, composta em diálogos entre "A" e "Z", discorre, de um extremo ao outro, sobre a imagem do protagonista. A riqueza e a aventura em que viveu são contadas pela primeira letra do alfabeto: seria o passado glorioso; a sua pobreza e a perda da originalidade são relatados pela última letra: seu estado presente de penúria. De "A" a "Z", fica-se conhecendo a ambiguidade da personagem. De um lado, tem-se o nababo, homem extravagante, de caráter singular e único, esquisito e caprichoso, que desperdiçava dinheiro à toa. Era o "Xavier especulativo". Do outro lado, tem-se um indivíduo sóbrio, poupado, que acorda com as galinhas, e apesar de não ser rico, também não chega a mendigo.

Diferente dos medalhões, que roubavam as ideias alheias, Xavier era um turbilhão de pensamentos, espalhando-os à revelia, na face de quem quisesse pescar. $E$ eram muitos os pescadores. Não partilhando da mentalidade geral - "odeio os carneiros de Panúrgio (v. 1, p. 374)" -, e gastando excessivamente, ele esvaziou. Possuía uma personalidade derramada, não dando o intervalo necessário da aposta, não sabendo a hora de parar. Nisso, até a sua imaginação secou. É curioso que a sua perda completa é historicamente datada em 1870, um dos momentos mais expansivos na economia e na cultura brasileira, depois da Guerra do Paraguai. "Foi ali por volta de 1869 ou 70, não me recordo; ele mesmo é que me contou. Tinha perdido tudo; trazia o cérebro gasto, chupado, estéril, sem a sombra de um conceito, de uma imagem, nada (v. 1, p. 376)". Num contexto fictício, mas também real, de emissões e ganâncias financeiras, o protagonista pode representar a ruína secular de alguns indivíduos do Império que mergulhando na nova ordem social foram sucumbidos por ela.

$\mathrm{Na}$ esperança que o destino sorrisse de volta, Xavier lançou o seu último tesouro no mar social, quer dizer, a derradeira ideia que brotou no seu ser, a qual compara a vida a "um cavalo xucro

\footnotetext{
${ }^{4} \mathrm{~A}$ lenda do rei Polícrates possui várias versões, entre elas a de Heródoto. As aventuras de Polícrates são rapidamente narradas no conto. Cf. HERÓDOTO. $O$ anel de Polícrates. Tradução de Rogério Hafez. In: $O$ anel de Polícrates e outras histórias. São Paulo, 2000. Disponível in: http://colegioobjetivocabreuva.com.br/Livros\%20objetivos/anel_de_policrates.pdf. Acesso em: 05 de nov. 2013.
} 
ou manhoso, e quem não for cavaleiro que o pareça" (v. 1, p. 378). Testando a fortuna, como fez 0 afortunado Polícrates, mas sem a mesma bem-aventurança, ele vê a sua ideia saltar de um lado para o outro, sendo utilizada aqui e acolá por terceiros, sem nunca conseguir tomar posse de seu pensamento novamente.

O caso extremo de uma natureza impulsiva e doentia, incapaz de adaptar-se a uma sociedade competitiva e desigual, estigmatizada por modelos de superioridade e inferioridade, encontra-se em Verba Testamentária. Nicolau tem um mal inato: a inveja. Corroído por ela, não consegue manter os padrões sociais por longo tempo. Tenta entrar na diplomacia, na política, casar-se, mas não consegue solidez. Enfim, ele procura acercar-se das grandes carreiras do tempo, porém a força do seu instinto 0 impede, morrendo verde, irritado e vesgo. Inábil para se lançar para fora, foi sugado para dentro de si até a morte.

\section{Considerações finais}

Machado de Assis faz da ficção o espéculo para observar as relações humanas, nas suas especificidades históricas e mais intrínsecas. Em razão disso, é a pluralidade que dá o tom das suas personagens, contendo sempre no gesto e no olhar a instabilidade.

Os seres fictícios do autor são históricos, manifestando no comportamento os contratempos e as vicissitudes da época; mas também são individuações, e estas não se esmorecem passivamente com as imposições sociais, mas se ajustam e se acoplam conforme a oportunidade que aparecem. Todavia, é preciso ressalvar que, em alguns casos, a natureza humana, não podendo com a força e os protótipos coletivos, é levada à mortificação, a exemplo de Nicolau.

Para Machado de Assis, a história é feita de indivíduo e interioridade. As relações de poder são igualmente orientadas por decisões e desejos pessoais. Se o tempo tem a grandeza de moldar os homens, estes têm a capacidade e a criatividade de tirar proveito da situação, e reinventar as circunstâncias históricas, pendendo os acontecimentos a seu favor.

\section{Referências}

ASSIS, Machado de. Esaú e Jacó. São Paulo: Penguin Companhia, 2012. Spinoza. In: A poesia completa. Organização de Rutzkaya Queiroz dos Reis. São Paulo: Edusp, 2009. Contos: uma antologia. São Paulo: Companhia das Letras, 1998. v. 1 e 2. BOSI, Alfredo. Machado de Assis: o enigma do olhar. 4. ed. São Paulo: Martins Fontes, 2007. 
. A máscara e a fenda. In: BOSI et al. Machado de Assis. São Paulo: Ática, 1982.

CANDIDO, Antonio. Esquema de Machado de Assis. In: Vários escritos. 4.ed. São Paulo: Duas cidade, 2004. Introdução. Formação da Literatura Brasileira. São Paulo: Martins Fontes, 1959, v. 1. CHALHOUB, Sidney. Machado de Assis, historiador. São Paulo: Companhia das Letras, 2003. COUTINHO, Afrânio. A formação filosófica e a atitude espiritual. Machado de Assis em linha: revista eletrônica de estudos machadianos, Rio de Janeiro, ano 4, n. 7, jun. 2011. Disponível em: <http://machadodeassis.net/download/numero07/num07artigo01.pdf> Acesso em: 11 de nov. 2013.

ESPINOSA, Baruch de. A origem e a natureza dos afetos. In: Ética. Tradução de Tomaz Tadeu. Belo Horizonte: Autêntica, 2008.

FAORO, Raymundo. Machado de Assis: a pirâmide e o trapézio. São Paulo: Brasiliana, 1974.

FREUD, Sigmund. O mal-estar na civilização. São Paulo: Penguin \& Comapnhia das Letras, 2011.

GLEDSON, John. A história do Brasil em Papéis avulsos, de Machado de Assis. In: Por um novo Machado de Assis: ensaios. São Paulo: Companhia das Letras, 2006.

HERÓDOTO. $O$ anel de Polícrates. Tradução de Rogério Hafez. In: 0 anel de Polícrates e outras histórias. São Paulo, 2000. Disponível in: <http://colegioobjetivocabreuva.com.br/Livros\%20objetivos/anel_de_policrates.pdf> Acesso em: 05 de nov. 2013.

JUNIOR, Caio Prado. História econômica do Brasil. São Paulo: Brasiliense, 2006.

OLIVEIRA, Fernando Bonadia de. O soneto "Spinoza" de Machado de Assis. In: GRASSET, B. Fragoso et al (orgs.). Spinoza e as Américas - X Colóquio Internacional Spinoza. Fortaleza: UECE, 2014, v. 1. PEREIRA, Astrojildo. Machado de Assis: ensaios e apontamentos avulsos. Rio de Janeiro: Livraria São José, 1959.

SCHWARRZ, Roberto. Um mestre na Periferia do capitalismo: Machado de Assis. São Paulo: Duas Cidades, 2000. 